\title{
INCLUSÄO, IDENTIDADE E O METODO DA CAPO, NA APRENDIZAGEM INSTRUMENTAL INICIAL DA FILARMÔNICA DO DIVINO, DO ESTADO DE SERGIPE
}

\section{Marcos dos Santos Moreira}

\section{RESUMO}

Para que possamos entender e refletir sobre educação musical especial em Sergipe através deste artigo que pretende fazer uma abordagem o processo de ensino do Projeto Filarmônica Coral e Escola de Música de Indiaroba, município que se localiza a $100 \mathrm{~km}$ de Aracaju, Estado de Sergipe. O objetivo do tema procede métodos de ensino musical instrumental comuns a alunos ditos normais. Perceber semelhanças nas diferenças de aprendizado em aluno especial dentro de projeto de Banda de Música.

\section{PALAVRAS-CHAVE}

Historia; Sociedade; Educação musical especial

\section{INCLUSION, IDENTITY AND METHODS OF CAPO, LEARNING INSTRUMENTAL IN INITIAL OF THE FILARMÔNICA DIVINO, THE RULE OF SERGIPE}

\begin{abstract}
So we can understand and reflect on musical education in particular through Sergipe This article aims to approach the process of teaching the Project Philharmonic Choir and School of Music, Indiaroba, the municipality that is located $100 \mathrm{~km}$ of Aracaju, state of Sergipe. The objective of the theme carries methods of teaching instrumental music students said the common standard.

Understanding similarities in the differences in student learning in particular within the project of Banda Music.
\end{abstract}

\section{KEYWORDS}

History; Society; Education musical special 


\section{HISTÓRIA DE INDIAROBA E DA FILARMÔNICA DO DIVINO}

Carinhosamente chamada pelos moradores de Índia Bela, o município de Indiaroba fica na região sul do Estado, a 102 quilômetros da capital sergipana, Aracaju, e possui cerca de 12.000 habitantes, tendo na atividade pesqueira seu principal ofício. Seu Povoado Pontal, foi "palco" do famoso romance Tieta do Agreste do escritor Jorge Amado, pois o município faz divisão de boa parte do território, a Mangue Seco, povoado de Jandaíra, cidade do norte da Bahia. Atualmente, a expansão turística do litoral da Bahia até Sergipe, com os complexos hoteleiros existentes e a abertura da Linha Verde ${ }^{1}$, tornou Indiaroba porta de entrada do Estado sergipano.

Já história da Filarmônica do Divino é bem mais recente. Surgida em 22 de maio de 2000 na gestão do então Prefeito Municipal Raimundo Mendonça de Araújo, é denominada assim por causa do padroeiro do município; o Divino Espírito Santo. É uma atividade pertencente aos objetivos educacionais propostos pela Secretaria de Educação, vinculada à prefeitura municipal sob coordenação do Departamento de Música do Centro Social da Paróquia do Espírito Santo (CSOPES). O CSOPES é uma entidade católica local de fins sócio-filantrópicos, que viabilizou o projeto junto a Prefeitura, em parceria com o "Projeto Bandas de Música" promovido pelo Governo Federal, através da Secretaria de Música do Ministério da Cultura, a Funarte e Governo do Estado de Sergipe por meio da Secretaria do Estado da Cultura.

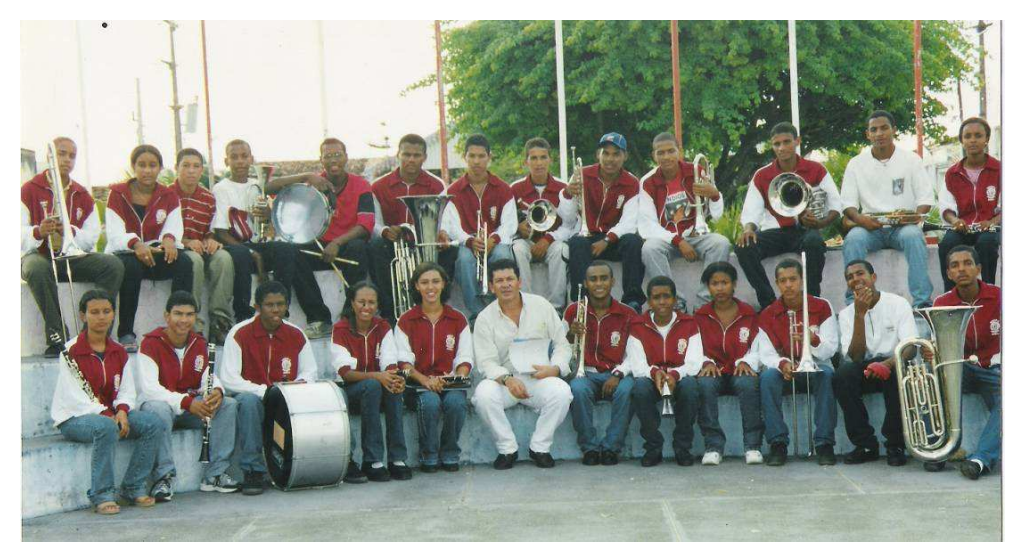

Fotografia histórica da $1^{\text {o }}$ formação da Banda Filarmônica do Divino em 07/09/2001. Ao centro, Maestro José Alípio Martins (Arquivo particular).

\footnotetext{
${ }^{1}$ Linha Verde: Estrada construída nos anos 90 que une Bahia e Sergipe pelo litoral, encurtando o trajeto entre as capitais em mais de meia hora (Salvador-Aracaju) em relação à antiga via $(\mathrm{Br}-101)$.
} 
A partir de então foi designado o $\operatorname{Prof}^{\circ}$ Marcos dos Santos Moreira, licenciado em Música pela UFBA e aprovado em concurso municipal indiarobense do referido ano para a vaga de educação artística. O mesmo foi designado o Coordenador de Arte e Diretor deste departamento, sendo depois também, seu regente no ano de 2004. O primeiro regente e responsável pela construção do processo pedagógico, foi o Maestro, formado pela Universidade Federal da Bahia, José Alípio Martins. Com sua saída em 2005, assumiu em 2006, Prof. João Paulo Lima. Na época, o Projeto de música também promoveu palestras ${ }^{2}$ e participou de matérias jornalísticas. Convidou à imprensa sergipana para documentar a referida Filarmônica através de veículos de comunicação locais nos jornais Cinform e Cidade, como também na TV em tema de documentário no programa "Sergipe Comunidade" da TV Sergipe (Filiada a Rede Globo) no ano de 2004. Atualmente, a Banda do Divino possui sede própria, continua suas atividades com muitos integrantes da primeira seleção, muitos deles já tocando como músicos profissionais

Hoje, 2007, a Filarmônica virou dissertação de Mestrado, intitulada Aspectos Históricos, sociais e pedagógicos das Filarmônicas do Divino e N.S. da Conceição, do estado de Sergipe, de autoria do Prof. Marcos dos Santos Moreira, pelo Programa de Pós Graduação da Universidade Federal da Bahia.

\section{CASO ABORDADO}

A primeira etapa seleção dos alunos-candidatos em 2000, estava imbuída de novidade para a comunidade local, afinal, era a primeira vez que se iniciava uma filarmônica na cidade. Não se podia excluir uma comunidade ansiosa por participar. Estipulou-se então uma faixa etária de 12 a 22 anos como média, de acordo com a própria média dos inscritos.

O discente exemplificado neste artigo foi aprovado na primeira seleção para tocar Clarineta. Porém tinha uma deficiência decorrente da falta de oxigenização cerebral que impossibilitava de acompanhar em sua vida escolar a mesma série recomendável para a sua idade. O aluno x tinha na época [2000-2004] $16 \operatorname{anos}^{3}$ e estava na $6^{a}$ série do ensino fundamental. Residia em Indiaroba mas estudava em escola religiosa particular, do município vizinho, Estância, à 15 km de Indiaroba.

\footnotetext{
${ }^{3}$ Período do aprendizado musical instrumental.
} 
Em relação a música, nenhum momento se fez restrições a sua inclusão no grupo filarmônico indiarobense. Apenas foi solicitado pela coordenação aos seus familiares, atestado médico, como ação preventiva no sentido de respiração, pois estaríamos trabalhando instrumentos de sopro que requer certo treinamento muscular e respiratório. A possibilidade de experimentarmos o método de ensino em um aluno especial foi interessante e desafiador. Afinal nenhum dos monitores tinha enfrentado tal desafio.

\section{O MÉTODO DA CAPO}

Historicamente fundamentado e baseado nos métodos modernos de ensino coletivo instrumental dos Estados Unidos, o Da Capo de Barbosa foi parte de sua tese de doutorado intitulada An Adaptation of American Instruction Methods to Brazilian Music Education: Using Brazilian Melodies de 1994. Já na sua publicação de 2004, o método foi intitulado Da Capo: Método elementar para ensino coletivo ou individual de instrumentos de banda. Neste mesmo ano o método foi editado pela Editora Keyboard com apoio da empresa de fabricação de instrumentos musicais Weril. Ele trabalha as habilidades instrumentais, de leitura e de se tocar em grupo com músicas folclóricas brasileiras aproximando os alunos-músicos de sua realidade melódica, diferentemente dos métodos tradicionais trazidos para o Brasil, baseados na Europa, particularmente Itália, Portugal e Alemanha, países historicamente ligados às Bandas de Música.

Basicamente o método é direcionado para a formação de banda sinfônica, mas pode ser adaptado facilmente para filarmônica. Por causa da estrutura do método para esta formação, alguns instrumentos são inclusos, como Trompa em Fá, Oboé e Fagote. É relevante o diferencial da leitura instrumental, no caso da escrita para Tuba. Normalmente em métodos convencionais, este instrumento está escrito em Si bemol, comum em bandas brasileiras. Mas pelo entendimento e direcionamento sinfônico, a Tuba ou Bombardão do Da Capo está em Dó. Em alguns casos, o Da Capo ainda encontra resistência a determinadas concepções. Esta resistência é observada em algumas filarmônicas interioranas tradicionais que, nos últimos anos, têm conhecido este processo didático. Nesses casos, os mestres dessas agremiações, mesmo buscando novas metodologias, na maioria das vezes, não aceitam tal processo de escrita para tuba. Alguns deles utilizavam o método modificando a escrita da Tuba para Si bemol, refazendo as partes relativas ao instrumento e alterando o método neste ponto. Hoje, o Da Capo já incorpora livros para diferentes escritas de tuba e bombardino. Em Indiaroba foi utilizado o livro de tuba para o instrumento em si bemol e escrito em dó, som real. 
A principal característica do método está no fato do aprendiz ter o contato com o instrumento desde a primeira aula e a possibilidade de formar, além da banda, conjunto menor, como duos, trios e quartetos, promovendo uma forte motivação nos alunos. Consiste em utilizar músicas folclóricas com células rítmicas simples, utilizando a teoria e a prática no instrumento simultaneamente, diferentemente do tradicional, que ensina o instrumento após o aprendizado da teoria e leitura musical. Do método, consta um livro-guia para o professormaestro e um livro para cada instrumento, da família das madeiras, metais e percussão. Os livros dos instrumentos são para os alunos e possuem 27 páginas cada. No livro do aluno constam 80 músicas do folclore brasileiro, 2 estudos para banda completa, 1 ditado melódico, 1 ditado rítmico, 2 exercícios para improvisação, exercícios de teoria, 2 arranjos de música folclórica para banda completa, 3 composições para banda, 3 estudos técnico-instrumentais e 8 exercícios de divisão musical.

\section{O DA CAPO EM KODÀLY E VIGOTSKY}

Se fizermos comparativos às filosofias e métodos tradicionalmente conhecidos de educação musical, identificaremos idéias, linhas de pensamento, semelhantes entre o método mencionado com o de Zoltan Kodaly (1882-1967), importante educador musical húngaro. Para Kodaly, a música deveria estar presente no sistema educacional como aspecto a ser desenvolvido pelo ser humano, visando a sua formação integral. Esta também é uma afirmação dos defensores do ensino coletivo, pois este ensino facilita a inclusão do aprendizado da música instrumental no ensino fundamental. Dois outros enfoques defendidos pelo método Da Capo e a metodologia de Kodaly, são a utilização da música folclórica, já acima citada, e o canto no processo de aprendizagem musical. Kodaly defende que: "É uma verdade longamente aceita o fato do canto ser o melhor início para a educação musical...a música folclórica não deve ser omitida nunca... o sentido das relações entre a linguagem e a música" (KODALY, 1974, p. 3) ${ }^{4}$

Nas instruções da utilização de aplicação Da Capo, Barbosa diz:

Tocar e cantar: Varie a ordem dessas duas atividades a cada canção nova a ser aprendida. Havendo dificuldade em entoar alguma canção, divida a classe em dois grupos, enquanto um toca o outro canta, e vice-versa. Se possível, use um instrumento harmônico (violão, piano, teclado, etc.) para acompanhar essas atividades. Procure cantar em tonalidades que sejam mais apropriadas para classe. (BARBOSA, 2004, p. 3).

\footnotetext{
${ }^{4}$ Tal referência traduzida pelo autor desta dissertação, se insere em prefácio da obra Children Choir's.
} 
Ao analisarmos os princípios do ensino coletivo de uma maneira ideológica geral, podemos dizer que esta metodologia musical pode se inspirar também em teóricos da Educação como Vigotsky ${ }^{5}$ (1896-1934), defensor da análise do reflexo do mundo exterior no mundo interior dos indivíduos. Este raciocínio do referencial educativo-social vigotskyano enfatiza a construção do conhecimento como uma interação mediada por várias relações. Essa interação age decisivamente na organização do raciocínio, reestruturando funções psicológicas como memória, atenção e formação de conceitos. Mais conhecida como "Relação Proximal", Vigotsky defende o aprendizado pela própria ação imediata e não somente pela expectativa da resposta ou análise do conteúdo dado, pois o fazer, já implica em um processo de aprendizagem..

Portanto o $D a$ Capo sendo um ensino musical coletivo proporciona a interação no contexto musical entre os aprendizes e eles com as ações de relações coletivas dessa prática.

\section{TÓPICOS DO PROCESSO PEDAGÓGICO}

1. Teoria musical aplicada na execução, 2. Percepção musical, 3. Estudo da harmonia, 4. Técnica individual de naipe, 5. Apreciação musical (Audição de peças), 6. Interpretação das peças, 7. Análise do contexto musical da região, 8. Canto das melodias folclóricas aprendidas.

Segundo o Maestro Martins, o grupo responderia satisfatoriamente se dividido em dois: Grupo I e Grupo II. O Grupo I responderia por um grupo titular, o grupo principal do projeto, a Filarmônica do Divino. O Grupo II seria aquele que abarcaria os alunos que não se desenvolveram satisfatoriamente nesta fase de iniciação instrumental e funcionava como uma Banda "reforço de aprendizes" ou reservas. Depois este grupo II se ampliou, naturalmente, pela inclusão de novos alunos. Não existia um critério em relação à data de entrada destes novos no início de um ano letivo, por exemplo. Isso acontecia periodicamente, pois as próprias apresentações do grupo titular serviam de certa forma como propaganda do projeto durante todo o ano para a comunidade. Apenas em 2004 é que houve a tentativa se estipular um ano letivo musical, mas a idéia não foi suficientemente sucedida.

\footnotetext{
${ }^{5}$ Vigotsky, professor e pesquisador; viveu na Rússia, em plena efervescência da Revolução Comunista. Tendo sido contemporâneo de Piaget, Vigotsky elaborou uma teoria que tem por base o desenvolvimento do indivíduo como resultado de um processo sócio-histórico e o papel de linguagem e da aprendizagem neste desenvolvimento.
} 


\section{A SOCIALIZAÇÃO E RESULTADOS OBTIDOS}

É relevante ressaltar que na questão da educação musical, especificamente no ensino coletivo, o fato de se trabalhar em grupo, cria uma socialização, e no caso da banda, há uma integração no âmbito escolar musical. Assim sendo, dentro da realidade onde um grupo musical é estabelecido, implica vivência de espaços de relações de grupo socialmente dadas. Estas relações vistas em alunos de um projeto, de uma banda, como indivíduos, promovem não só o aprendizado da música, mas formas de pensar, sentir e agir, garantidoras de práticas sócio-educativas.

$\mathrm{Na}$ verdade em todo o processo de aprendizado inicial que durou dois anos, em três etapas, não apresentou em X nenhum problema psicomotor ou articulativo, ou embocadura e até mesmo não se "esbarrou" em respirações diafragmáticas ou embocadura, dificuldades relativas ao seu instrumento.

O aluno especial abordado, já arrisca não só a clarineta como também o sax alto. Segundo sua genitora, depois da sua entrada na banda, houve um desenvolvimento também na sua vida escolar, se aproximando da sua série ideal, ou melhor, se aproximando da relação idade/série, além de outros aspectos de relação social e cognitiva.

\section{REFERÊNCIAS}

ANJOS, M. F. O. Festa do Divino Espírito Santo, Padroeiro de Indiaroba (1970-1990). 2001. Monografia (Licenciatura em História) - Centro de Educação e Ciências Humanas, Universidade Federal de Sergipe, São Cristóvão, 2001.

AROM, S. Inteligência na musica tradicional. A natureza da inteligência. São Paulo: Unesp/Cambridge University Press, 1994.

\section{BARBOSA, J. L. S. Adaptation of American Instruction Methods to Brazilian Music}

Education Using Brazilian Melodies. 1994. Tese (Doutorado) - University of WashingtonSeattle, Washington, 1994.

Da Capo: Método elementar para ensino Coletivo ou individual de instrumentos de banda. Primeira versão, trabalho não publicado. Salvador: 2000.

Da Capo: Método elementar para ensino Coletivo ou individual de instrumentos de banda. São Paulo: Keyboard, 2004. 


\section{PESQUISA \\ Área Temática: Educação \& Arte}

MOREIRA, M. Aspectos históricos, socias e pedagógicos nas filarmônicas do Divino e

Nossa Senhora da Conceição, no estado de Sergipe. Dissertação (Mestrado) - Universidade Federal da Bahia, Salvador, 2007.

SERGIPE COMUNIDADE: A Filarmônica de Indiaroba, produção TV Sergipe. Aracaju [s.n,2004] fita de vídeo ( $12 \mathrm{~min}$ ), VHS, son.,Color.

Mestre e Licenciado em Música (Educação Musical) pela Universidade

Federal da Bahia. Fundador da $1^{\text {a }}$ Banda de Música do município de Indiaroba-Se tem atuado como docente nas áreas de Instrumento/ Piano, Educação Especial e ensino de pós-graduação de Arte-educação. Constam publicações suas em Anais de Encontros e Simpósio nacionais e Internacionais de Música, Psicologia e Educação musical especial. Obteve classificação em diversos concursos de Educação / Música e apresentado

comunicações nos estados da Bahia, Alagoas, Sergipe, Paraíba e São

Paulo. Sua linha de pesquisa baseia-se em Educação/ Sociedade/ Arte.

E-mail: m.moreira73@ig.com.br 